\title{
Efeito da solarização do solo, seguida pela aplicação de Trichoderma spp. ou de fungicidas, sobre o controle de Pythium aphanidermatum e de Rhizoctonia solani AG-4
}

\author{
Flávia Rodrigues Alves Patrício ${ }^{1}$, Hiroshi Kimati ${ }^{2}$, João Tessarioli Neto ${ }^{3}$, Ademir Petenatti ${ }^{4}$, Benedito Camargo Barros ${ }^{1}$.
}

${ }^{1}$ Instituto Biológico, CP 70, CEP 13001-970, Campinas, SP, e-mail:flavia@biologico.sp.gov.br. ${ }^{2}$ Departamento de Entomologia, Fitopatologia e Zoologia, ESALQ-USP, CP 9, CEP 13418-900. ${ }^{3}$ Departamento de Produção Vegetal, ESALQ-USP, CP 9, CEP 13418-900, ${ }^{4}$ Departamento de Estatística, UNICAMP, CP 6065, CEP 13083-970, Campinas, SP.

* Parte da tese de doutorado do primeiro autor.

Autor para correspondência: Flávia Rodrigues Alves Patrício

Data de chegada: 14/09/2005. Aceito para publicação em: 10/11/2006.

1251

\section{RESUMO}

Patrício, F.R.A., Kimati, H., Tessarioli Neto, J., Petenatti, A. \& Barros, B.C. Efeito da solarização, associada à aplicação de Trichoderma spp. ou fungicidas, sobre o controle de Pythium aphanidermatum e de Rhizoctonia solani AG-4. Summa Phytopathologica, v.33, n.2, p.142-146, 2007.

O presente trabalho foi realizado com o objetivo de estudar alternativas para a desinfestação de solos, especialmente considerando a retirada do brometo de metila do mercado. Avaliou-se o efeito da solarização do solo, seguida ou não pela aplicação de isolados de Trichoderma spp. ou de fungicidas, sobre o controle de Pythium aphanidermatum e de Rhizoctonia solani AG-4, responsáveis por tombamento e podridão de raízes em várias culturas. Dois experimentos foram realizados em Piracicaba, SP (latitude $22^{\circ} 42^{\prime}$ e longitude $47^{\circ} 38^{\prime}$ ), um em campo aberto e outro no interior de uma casa-de-vegetação vedada, em delineamento em blocos casualizados, em esquema fatorial (2x3), tendo como fatores a solarização (com e sem) e os tratamentos (com fungicida, um isolado de Trichoderma sp. e uma testemunha). Bolsas de náilon contendo solo naturalmente infestado com $P$. aphanidermatum ou solo contendo propágulos de $R$. solani AG-4 foram enterradas a $10 \mathrm{~cm}$ de profundidade, em parcelas solarizadas ou não, nos dois ambientes. Após 30 dias de solarização, as bolsas foram coletadas e o solo infestado com $P$. aphanidermatum recebeu os tratamentos: o isolado de Trichoderma sp. IB-26 ou o fungicida metalaxyl + mancozeb. O solo contendo propágulos de $R$. solani foi tratado com o isolado de Trichoderma sp. IB-17 ou o fungicida pencycuron. As soluções dos fungicidas foram aplicadas na forma de rega. Também foram mantidas testemunhas para ambos os patógenos. Avaliou-se a viabilidade de $P$. aphanidermatum pelo tombamento de pós-emergência de plântulas de pepino e de $R$. solani pelo número de plântulas de rabanete sobreviventes ao tombamento de pré e pós-emergência. A solarização, o controle biológico e a solarização seguida pelo controle biológico não promoveram o controle de $P$. aphanidermatum, obtido apenas com metalaxyl + mancozeb, nos solos solarizados ou não. A solarização aplicada nos dois ambientes controlou $R$. solani, assim como o fungicida pencycuron, mas não houve efeito sinérgico na associação entre as técnicas. A aplicação do isolado de Trichoderma sp. IB-17 não proporcionou o controle desse patógeno nos solos solarizados ou não.

Palavras-chave adicionais: controle biológico, controle químico, desinfestação de solo.

\section{ABSTRACT}

Patrício, F.R.A., Kimati, H., Tessarioli Neto, J., Petenatti, A. \& Barros, B.C. Effect of soil solarization, followed or not by the application of Trichoderma spp. or fungicides for the control of Pythium aphanidermatum and Rhizoctonia solani AG-4. Summa Phytopathologica, v.33, n.2, p.142-146, 2007.

The development of alternative strategies for soil desinfestation with methyl bromide is necessary since the use of this compound faces increasing restrictions worldwide. Therefore the effect of soil solarization, followed by the application of isolates of Trichoderma spp. or fungicides, was evaluated for the control of Pythium aphanidermatum and Rhizoctonia solani, both can cause damping-off and root rots of several crops. Two experiments were carried out, one under greenhouse conditions and the other one under field conditions, both in a randomized block design, in factorial scheme $(2 \times 3)$, involving the combination of soil solarization (solarized and non-solarized soils) and the application of chemical or biological treatments, plus controls. Nylon bags containing soil naturally infested with $P$. aphanidermatum or soil with propagules of $R$. solani AG-4 were buried at $10 \mathrm{~cm}$ soil depth in plots solarized or non-solarized. After 30 days of solarization the bags were collected and the soil infested with P. aphanidermatum was treated with Trichoderma sp. (isolate IB-26) or with the fungicide metalaxyl + mancozeb, whereas the soil containing propagules of $R$. solani received an isolate of Trichoderma sp. (isolate IB-17) or the fungicide pencycuron. Fungicide suspensions were irrigated over the soil. A control was maintained for the soils infested with both pathogens. Viability of P. aphanidermatum and $R$. solani was evaluated by post-emergence damping-off of cucumber seedlings and by pre and post-emergence damping-off of radish seedling, respectively. Soil solarization, the biological treatment and the association of both treatments had no effect on the control of P. aphanidermatum, which was achieved only by the treatment with metalaxyl + mancozeb in the solarized and non-solarized soil. Soil solarization applied in both environments as well as the fungicide pencycuron were effective to control $R$. solani, but the association of both treatments did not have any synergistic effect. The treatment with the isolate of Trichoderma sp. IB-17 had no effect on $R$. solani, and was not favored by soil solarization.

Additional keywords: biological control, chemical control, soil disinfestation. 
Áreas intensa e sucessivamente cultivadas, como as ocupadas com hortaliças e ornamentais, em cultivos protegidos ou não, podem se tornar infestadas por patógenos veiculados pelo solo, como Pythium aphanidermatum e Rhizoctonia solani. Esses microrganismos estão associados a tombamento e podridões nas raízes e no colo de muitas espécies (5). São patógenos que apresentam grande capacidade saprofítica (15) e produzem estruturas de resistência, $P$. aphanidermatum forma oosporos (2) e $R$. solani produz escleródios (15), que aumentam a sobrevivência no solo e dificultam o controle dos mesmos (15).

O controle de $P$. aphanidermatum e $R$. solani pode ser obtido pela desinfestação de solos e substratos para a produção de mudas com vapor, brometo de metila ou a aplicação de fungicidas nas sementes ou nas plântulas recém-emergidas, antes e depois do transplante $(5,15)$. $\mathrm{O}$ brometo de metila apresenta as vantagens de necessitar de apenas uma semana para o tratamento e ter amplo espectro de ação sobre fitopatógenos, pragas e plantas daninhas $(5,11)$. Entretanto, esse composto encontra-se entre os apontados como responsáveis pela redução da camada de ozônio da atmosfera (27), e, por esse motivo, restrições ao seu uso têm sido impostas, e vários países têm procurado desenvolver técnicas alternativas para a sua substituição (27).

A solarização do solo é uma alternativa para a desinfestação de solos e substratos (13), que pode ser aplicada em campo e também em ambientes protegidos $(13,19)$. A técnica consiste na colocação de um filme plástico transparente sobre o solo umedecido, durante o período do ano de maior radiação solar, com o objetivo de promover o aumento da sua temperatura (13). Durante o processo, as temperaturas atingem níveis letais nas camadas superficiais do solo e sub-letais nas mais profundas a muitos fitopatógenos, pragas e plantas daninhas (13). Ocorrem alterações biológicas, químicas e físicas, que resultam, freqüentemente, em aumento de produção das culturas (13). Embora o processo promova o controle de muitos fitopatógenos, a associação da solarização a outros métodos de controle tem sido proposta, visando aumentar a eficiência da técnica e/ou do outro método (12).

Em alguns estudos a solarização foi associada ao controle químico, especialmente com produtos destinados à desinfestação do solo, como brometo de metila, dazomet, methan-sodio, tendo como resultado maior eficiência do controle ou redução no período do tratamento e/ou na dose do produto (12). A técnica também foi associada a fungicidas, com resultados positivos para o controle de Sclerotinia minor em alface (28).

A associação da solarização a agentes de biocontrole pode ser especialmente interessante (12), pois a técnica, ao reduzir ou alterar a atividade da comunidade microbiana do solo, pode favorecer a introdução de microrganismos antagônicos (29), mesmo que após o tratamento ainda permaneçam no solo populações com considerável atividade microbiana (7). A elevação na temperatura do solo pode erradicar ou enfraquecer os propágulos de fitopatógenos, que se tornam mais suscetíveis à ação dos agentes de biocontrole (7). Outro importante fato é que a recolonização de solos desinfestados com antagonistas pode ser uma estratégia para aumentar a supressividade dos mesmos a fitopatógenos (7). A associação da solarização a isolados de Trichoderma spp. apresentou resultados positivos, sendo superior a ambos os métodos quando aplicados isoladamente para o controle de Sclerotium cepivorum (24) e de $R$. solani $(3,4)$.

A retirada do brometo de metila do mercado torna necessário o desenvolvimento de alternativas para a desinfestação de solos em áreas freqüentemente cultivadas, tais como os ambientes protegidos. A solarização apresenta grande potencial para o tratamento de solos em regiões tropicais e pode ter sua eficiência ampliada ao ser associada a outros métodos de controle, como o biológico ou o químico. Por estas razões o presente trabalho estudou o efeito da solarização, aplicada em casa-de-vegetação e em campo aberto, e da sua associação a isolados de Trichoderma spp. ou a fungicidas sobre o controle de $P$. aphanidermatum e de $R$. solani.

\section{MATERIAL E MÉTODOS}

Inicialmente foram preparadas separadamente bolsas de tela de náilon contendo solo naturalmente infestado com $P$. aphanidermatum e solo misturado a propágulos de $R$. solani. O solo naturalmente infestado com $P$. aphanidermatum foi coletado na área experimental do Departamento de Produção Vegetal da ESALQ-USP, 10 a 15 dias antes do início dos experimentos, sendo seco à sombra, peneirado e colocado nas bolsas de náilon ( 0,5 litro de solo peneirado por bolsa).

Utilizou-se um isolado de $R$. solani AG-4 obtido de feijoeiro, procedente do município de Pompéia, SP. Discos retirados das bordas de colônias crescidas em meio BDA, com aproximadamente cinco dias, foram colocados em Erlenmeyers, contendo grãos de trigo umedecidos ( $100 \mathrm{~g}$ de sementes de trigo/75 $\mathrm{mL}$ de água) e autoclavados (1,5 atm, a $120^{\circ} \mathrm{C}$ por uma hora, em dois dias consecutivos). Os frascos foram incubados por 10 dias em ambiente de laboratório, até que os grãos fossem recobertos pelo micélio do patógeno. Em seguida foram preparadas bolsas de náilon contendo cada uma $10 \mathrm{~g}$ dos grãos colonizados, misturados a $0,5 \mathrm{~L}$ de solo coletado na área experimental do Instituto Biológico. Para possibilitar a identificação das bolsas contendo os fitopatógenos, cada bolsa foi amarrada a um cordão plástico e etiquetada.

Dois experimentos de solarização foram realizados, um no interior de uma casa-de-vegetação coberta com filme plástico transparente ( $150 \mathrm{~mm}$ de espessura com aditivo estabilizador de raios ultravioleta) e revestida lateralmente com sombrite, e outro em local próximo em campo aberto, ambos em área experimental do Departamento de Produção Vegetal da ESALQ-USP, em Piracicaba, SP (latitude $22^{\circ} 42^{\prime}$ e longitude $47^{\circ} 38^{\prime}$.) Uma área de 28 x 8 metros da casa-de-vegetação teve as paredes laterais vedadas com plástico transparente $(100 \mathrm{~mm}$ de espessura), para aumentar a temperatura no seu interior. A área foi dividida em quatro blocos (14 x 3,5 m) e cada bloco continha duas parcelas ( 7 X 3,5 m), uma solarizada e outra não. Uma área externa, localizada a 10 metros da casa-de-vegetação, foi preparada e dividida da mesma forma. As amostras contendo os propágulos de $P$. aphanidermatum e de $R$. solani foram dispostas de maneira casualizada sobre as áreas a serem solarizadas ou não, dentro e fora da casa-devegetação, mantendo-se uma distância mínima de $40 \mathrm{~cm}$ das bordas, e enterradas a $10 \mathrm{~cm}$ de profundidade. $\mathrm{O}$ solo de todas as parcelas foi umedecido até próximo à capacidade de campo. A solarização foi realizada no período de 26 de fevereiro a 25 de março de 1999, com um filme plástico transparente de $100 \mu \mathrm{m}$ de espessura, que teve as bordas enterradas a aproximadamente $20 \mathrm{~cm}$ de profundidade para evitar a perda de calor. Durante a solarização, todas as parcelas não solarizadas foram umedecidas periodicamente e a temperatura do solo foi registrada no centro de cada parcela por meio de termômetros de solo (mercúrio) que tinham os bulbos enterrados a $10 \mathrm{~cm}$ de profundidade.

Cada experimento, dentro e fora da casa-de-vegetação, foi realizado em delineamento em blocos casualizados e analisado em esquema fatorial $(2 \times 3)$, tendo como fatores a solarização, com e sem, e os tratamentos, controle químico, controle biológico, além das testemunhas, sem tratamento adicional.

Após 30 dias de solarização, foram coletadas, de cada parcela, três bolsas contendo o solo naturalmente infestado com P. aphanidermatum. 
O solo de cada bolsa foi colocado em um copo plástico de $0,75 \mathrm{~L}$. O solo de uma bolsa de cada parcela foi misturado a cinco gramas de grãos de trigo colonizados com um isolado de Trichoderma sp. (IB26), previamente selecionado como antagonista a $P$. aphanidermatum (22). Os solos dispostos nos copos plásticos foram umedecidos com 0,125 L de água e incubados por dez dias em casa-de-vegetação, para favorecer a colonização do solo pelo antagonista. Paralelamente foram preparadas caixas plásticas de $20 \times 30 \times 15 \mathrm{~cm}$, contendo aproximadamente $1,5 \mathrm{~L}$ de solo desinfestado (autoclavado a $120^{\circ} \mathrm{C}$ por 3 horas) e 100 plântulas recém-emergidas de pepino da variedade Caipira. O conteúdo de cada copo plástico foi misturado a $10 \mathrm{~g}$ de farinha de aveia, para servir como fonte de nutrientes para o patógeno, e, em seguida, distribuído uniformemente no colo das plântulas de pepino de cada bandeja, de acordo com metodologia adaptada de Lourd et al. (18). O tratamento químico foi efetuado a seguir. As caixas correspondentes a este tratamento foram dispostas em uma área de um $\mathrm{m}^{2}$ delimitada no chão, na qual foram uniformemente distribuídos, por meio de regador, dois litros de calda preparada com metalaxyl + mancozeb na dose de $12+96 \mathrm{~g}$ de i.a., respectivamente, por $100 \mathrm{~L}$ de água. As caixas correspondentes às testemunhas solarizadas e não solarizadas permaneceram sem tratamento adicional. Estimou-se a viabilidade do patógeno pela porcentagem de tombamento, calculada com base no número de plântulas tombadas e sobreviventes ao tombamento, quatro a sete dias depois da colocação dos solos nas bandejas.

Também foram coletadas, de cada parcela, as três bolsas contendo os propágulos de $R$. solani, sendo o conteúdo de cada bolsa colocado em um copo plástico de $0,75 \mathrm{~L}$. O solo de um copo plástico de cada parcela foi misturado a cinco gramas de grãos de trigo colonizados com o isolado de Trichoderma sp. (IB-17), previamente selecionado como antagonista a $R$. solani (22). Os solos dispostos nos copos plásticos foram umedecidos com $0,125 \mathrm{~L}$ de água e incubados por dez dias em casa-de-vegetação, para favorecer a colonização do solo pelo antagonista. Após esse período, vasos de $20 \mathrm{~cm}$ de diâmetro e $15 \mathrm{~cm}$ de altura foram preparados com um litro de solo autoclavado, sobre o qual foram uniformemente distribuídas 50 sementes de rabanete. Essas foram cobertas com $200 \mathrm{~mL}$ do solo contido nos copos. O solo de cada bolsa foi utilizado para cobrir dois vasos, que constituíram uma repetição. A seguir foi realizado o tratamento químico. Os vasos correspondentes a esse tratamento foram dispostos ao acaso no chão, em uma área delimitada de $\mathrm{um}^{2}$, efetuando-se a rega uniforme dos mesmos com quatro litros de uma calda preparada com pencycuron na dose de $50 \mathrm{~g}$ de i.a. por $100 \mathrm{~L}$ de água. Os vasos correspondentes às testemunhas solarizadas e não solarizadas de cada parcela permaneceram sem tratamento adicional. Estimou-se a viabilidade do patógeno pelo número de plântulas que emergiram e que sobreviveram ao tombamento de pós-emergência, contando-se o número de plântulas vivas dez dias após o plantio.

\section{RESULTADOS E DISCUSSÃO}

Nos experimentos realizados na casa-de-vegetação e no campo, a solarização e a solarização seguida pela aplicação do isolado de Trichoderma sp. não promoveram o controle de $P$. aphanidermatum (Tabela 1). O controle desse patógeno somente foi obtido nos tratamentos com metalaxyl + mancozeb (Tabela 1), mesmo tendo sido empregada metade da dose recomendada do produto. O tratamento com metalaxyl + mancozeb foi tão eficiente que não houve benefício na associação do fungicida com a solarização. Metalaxyl + mancozeb é um conhecido anti-oomiceto que demonstrou eficiência para o controle de $P$. aphanidermatum em plântulas de pepino e de outras espécies (23).

No presente trabalho, a solarização não promoveu o controle de $P$. aphanidermatum, embora em estudos anteriores, espécies de Pythium tenham perdido a viabilidade após serem submetidas à solarização no campo nas culturas do crisântemo (1), do algodão (25) e, em casa-devegetação, do pepino (17). Embora P. ultimum e espécies de Pythium estejam listadas entre os fitopatógenos controlados pela solarização $(13,29), P$. aphanidermatum está incluído entre os parcialmente ou não controlados pela técnica (29), como verificado nos presentes experimentos. Esse fato ocorreu, provavelmente, porque essa espécie apresenta temperatura letal maior que $52,5^{\circ} \mathrm{C}$, após 30 minutos de exposição da cultura misturada a solo a essa temperatura (2), superior à temperatura máxima de $49,3{ }^{\circ} \mathrm{C}$ atingida nos solos solarizados nos dois ambientes estudados neste trabalho (Tabela 2). O patógeno $P$. aphanidermatum deve ser resistente a temperaturas elevadas provavelmente porque, além de ser um microrganismo freqüentemente associado a solos tropicais (18), causando maiores danos a $35^{\circ} \mathrm{C}$ do que a $25^{\circ} \mathrm{C}(27)$, forma oosporos, que aumentam a sua capacidade de sobrevivência em condições ambientais adversas, tais como temperaturas elevadas (2).

No experimento realizado na casa-de-vegetação não houve interação entre os tratamentos (Trichoderma spp. e fungicidas) e a solarização, sendo significativo apenas o fator tratamentos (Probabilidade $>\mathrm{F}=$

Tabela 1. Viabilidade de Pythium aphanidermatum, estimada pelo número de plântulas de pepino sobreviventes ao tombamento de pós-emergência, após a solarização, efetuada no período de 26 de fevereiro a 25 de março de 1999, seguida de incorporação ao solo de Trichoderma sp. ou aplicação de metalaxyl + mancozeb, em experimentos realizados em condições de casa-de-vegetação e campo, em Piracicaba, SP.

Tratamentos

\begin{tabular}{llccc} 
Local & Tratamentos & Controle & Metalaxyl + mancozeb ${ }^{1}$ & Trichoderma sp (Isolado IB - 26) \\
\hline Casa-de-vegetação & Solo solarizado & $29,9 \mathrm{~b} \mathrm{~A}^{3}$ & $100,0 \mathrm{a} \mathrm{A}$ & $46,4 \mathrm{~b} \mathrm{~A}$ \\
& Solo não solarizado & $64,8 \mathrm{a} \mathrm{A}$ & $100,0 \mathrm{a} \mathrm{A}$ & $30,9 \mathrm{~b} \mathrm{~A}$ \\
CV (\%) & & 35,8 & $27,2 \mathrm{~b} \mathrm{~B}$ \\
Campo & Solo solarizado & $49,6 \mathrm{~b} \mathrm{~A}$ & $100,0 \mathrm{a} \mathrm{A}$ & 56,3 b A \\
CV (\%) & Solo não solarizado & $47,4 \mathrm{~b} \mathrm{~A}$ & $100,0 \mathrm{a} \mathrm{A}$ & 18,3 \\
\hline
\end{tabular}

\footnotetext{
${ }^{1}$ Metalaxyl + mancozeb aplicado na forma de rega na dose de $150 \mathrm{~g}$ de p.c./100L de água;

${ }^{2}$ Porcentagem de plântulas de pepino sobreviventes ao tombamento de pós-emergência;

${ }^{3}$ Médias comparadas pelo teste de Tukey a $5 \%$ de probabilidade. Letras minúsculas comparam médias na horizontal e maiúsculas na vertical.
} 
Tabela 2. Temperaturas médias e máximas registradas nos solos às 15:00 horas em condições de casa-de-vegetação e campo, a $10 \mathrm{~cm}$ de profundidade, em experimentos realizados no período de 26/02 a 25/03/1999. Piracicaba, SP.

\begin{tabular}{|c|c|c|c|c|c|}
\hline \multirow[t]{3}{*}{ Horário } & \multirow[t]{3}{*}{ Ambiente } & \multicolumn{4}{|c|}{ Temperaturas do solo $\left({ }^{\circ} \mathrm{C}\right)$ a $10 \mathrm{~cm}$ de profundidade } \\
\hline & & \multicolumn{2}{|c|}{ Solo solarizado } & \multicolumn{2}{|c|}{ Solo não solarizado } \\
\hline & & Médias & Máximas & Médias & Máximas \\
\hline \multirow[t]{2}{*}{$15: 00 \mathrm{~h}$} & Casa-de-vegetação & 41,5 & 49,3 & 35,3 & 40,5 \\
\hline & Campo & 44,5 & 49,3 & 33,0 & 38,1 \\
\hline
\end{tabular}

0,0003). Por outro lado, no ensaio efetuado no campo, houve interação entre os fatores (Probabilidade $>F=0,0,0342$ ), possivelmente porque o número de plântulas de pepino que sobreviveram ao tombamento foi significativamente menor no tratamento que empregou a solarização seguida pelo controle biológico (Tabela 1).

Em ambos os experimentos, o tratamento com o isolado de Trichoderma sp. IB-26 não promoveu o controle de $P$. aphanidermatum (Tabela 1) e a solarização não favoreceu a ação do agente de biocontrole. Esse isolado não foi eficiente no presente trabalho, embora tenha sido previamente selecionado como antagonista a $P$. aphanidermatum (23). Pode ser que antagonistas termotolerantes selecionados durante a solarização inviabilizaram a colonização do solo por este isolado, ou que o isolado perdeu a capacidade de antagonismo durante as etapas de multiplicação em laboratório. Um dos inconvenientes do controle biológico é a grande variabilidade encontrada no desempenho de um mesmo isolado em diferentes experimentos, fato verificado por Koch (14) ao empregar produtos comerciais formulados com isolados de Trichoderma ou Gliocladium para o controle de P. ultimum em substrato e por Ousley et al. (21) ao estudarem o estímulo ao desenvolvimento de plantas de alface por alguns isolados de Trichoderma spp. Esses últimos autores atribuíram essa variabilidade a características intrínsecas de alguns isolados, que demonstram menor estabilidade durante as etapas de multiplicação em laboratório.

Em ambos os experimentos, a solarização promoveu o controle de $R$. solani (Tabela 3). Este resultado era esperado, pois o patógeno apresenta maior sensibilidade térmica que espécies de Pythium (25). Lefèvre \& Souza (16) verificaram a inativação térmica de $R$. solani após a exposição do micélio à temperatura de $50^{\circ} \mathrm{C}$ por 30 minutos. A temperatura máxima $\left(49,3^{\circ} \mathrm{C}\right)$ registrada nos solos solarizados dentro e fora da casa-de-vegetação no presente trabalho (Tabela 2), foi suficiente para promover o controle do patógeno, fato que havia sido observado em outros experimentos de solarização realizados em campo $(10,25)$ e em casas-de-vegetação $(6,9)$.

Nos presentes experimentos, a solarização foi tão eficiente para o controle de $R$. solani que a sua posterior associação ao fungicida não foi vantajosa, fato também verificado por Sinigaglia et al. (28) ao associarem a técnica a pencycuron, aplicado duas vezes durante a condução da cultura da alface, para o controle da queima-da-saia, causada por $R$. solani AG-1-1. Por outro lado nas parcelas não solarizadas, tanto nestes experimentos (Tabela 3 ), quanto no realizado por Sinigaglia et al. (28), pencycuron reduziu a viabilidade do patógeno, mostrando-se um método de controle interessante para as situações em que a solarização não pode ser empregada.

No ensaio efetuado na casa-de-vegetação apenas o fator solarização foi significativo (Probabilidade $>\mathrm{F}=0,0101$ ) e não houve interação entre os fatores solarização e tratamentos. Por outro lado na área externa, a interação entre a solarização e os tratamentos foi significativa (Probabilidade $>\mathrm{F}=0,0012$ ), provavelmente porque as diferenças entre as parcelas solarizadas e não solarizadas foram maiores.

A incorporação do isolado de Trichoderma sp. IB-17 aos solos solarizados e não solarizados não promoveu o controle de $R$. solani, como verificado para $P$. aphanidermatum, embora o isolado IB-17 tenha sido previamente selecionado como antagonista a esse patógeno (22). Assim como ocorreu para o isolado IB-26, o isolado IB-17 também pode ter perdido a capacidade de antagonismo durante as etapas de multiplicação em laboratório ou pode ter sido incapaz de recolonizar o solo solarizado.

A solarização foi tão eficiente para o controle de $R$. solani em ambos os ambientes, que não houve benefício adicional na posterior incorporação do isolado de Trichoderma sp. IB-17, semelhante ao observado por Minuto et al. (20), em campo, e Garibaldi \& Tamieti (6) em casa-de-vegetação. Por outro lado, em outros experimentos, a incorporação de Trichoderma após a solarização foi vantajosa para o controle de $R$. solani $(3,4)$ e de Sclerotium cepivorum (24).

Em outros países já há consenso de que a substituição do brometo de metila é complexa e ocorrerá, provavelmente, por meio da adoção de diferentes métodos de controle, associados ou não $(8,11)$, para os quais ainda são necessárias extensas pesquisas. Um importante aspecto que deverá ser considerado é o diagnóstico prévio dos fitopatógenos

Tabela 3. Viabilidade de Rhizoctonia solani AG-4, avaliada pelo número de plântulas de rabanete sobreviventes ao tombamento de pré e pós-emergência, após a solarização, efetuada de 26 de fevereiro a 25 de março de 1999, seguida da incorporação ao solo de Trichoderma sp. ou do tratamento com pencycuron, em experimentos efetuados em condições de casa-de-vegetação e campo, em Piracicaba, SP.

\begin{tabular}{|c|c|c|c|c|}
\hline Local & Solarização & Controle & Pencycuron $^{1}$ & Trichoderma sp (Isolado IB - 17) \\
\hline Casa-de-vegetação & S. solarizado & $87,3^{2} \mathrm{a} \mathrm{A}^{3}$ & 85,8 a $\mathrm{A}$ & 87,8 a $\mathrm{A}$ \\
\hline $\mathrm{CV}(\%)$ & & & 6,4 & \\
\hline Campo & S. solarizado & 90,8 a $\mathrm{A}$ & 89,8 a $\mathrm{A}$ & 90,8 a $\mathrm{A}$ \\
\hline & S. não solarizado & $59,0 \mathrm{~b}$ B & 81,5 a $\mathrm{A}$ & $63,5 \mathrm{~b} \mathrm{~B}$ \\
\hline
\end{tabular}

\footnotetext{
${ }^{1}$ Pencycuron aplicado por rega na dose de 200 g p.c./100 L de água;

${ }^{2}$ Porcentagem de plântulas de rabanete sobreviventes ao tombamento de pré e pós-emergência;

${ }^{2}$ Médias comparadas pelo teste de Tukey a $5 \%$ de probabilidade. Letras minúsculas comparam médias na horizontal e maiúsculas na vertical.
} 
presentes na área a ser desinfestada, que determinará a escolha das técnicas a serem aplicadas e/ou de suas associações, o que no passado não tinham tanta importância, por causa do amplo espectro de atuação do brometo de metila (11).

Os dados obtidos no presente trabalho podem não prever com exatidão o que ocorre em condições naturais, pois se tratam de experimentos de solarização com amostras de solo infestado ou contendo propágulos de patógenos, dispostas em bolsas de náilon e enterradas (12), mas fornecem importantes informações sobre o potencial das técnicas aplicadas e de suas associações. A solarização promoveu o controle de $R$. solani na casa-de-vegetação e no campo, porém as temperaturas atingidas não foram suficientes para a inativação de $P$. aphanidermatum. Não houve benefício na associação entre a solarização e o controle biológico, tratamento que não foi eficiente para $P$. aphanidermatum e $R$. solani, patógenos controlados pela aplicação de fungicidas no solo, tratamento que não inviabiliza a área para cultivo.

\section{REFERÊNCIAS BIBLIOGRÁFICAS}

1. Bettiol, W.; Ghini, R.; Galvão, J.A.H. Solarização do solo para o controle de Pythium e plantas daninhas em cultura do crisântemo. Scientia Agricola, Piracicaba, v.51, p.459-462, 1994.

2. Bollen, G.J. Lethal temperatures of soil fungi. In: Parker, C.A.; Rovira, A.D.; Moore, K.J.; Wong, P.T.W. (Ed.) Ecology and management of soilborne plant pathogens. St. Paul: The American Phytopathological Society, 1985. cap.5, p.191-193.

3. Chet, I.; Elad, Y.; Kalfon, A.; Hadar, Y.; Katan, J. Integrated control of soilborne and bulbborne pathogens in iris. Phytoparasitica, Tel Aviv, v. 10, n. 4, p.229-236, 1982.

4. Davis, J.R. Soil solarization; pathogen and disease control and increases in crop yield and quality: short-and-long-term effects and integrated control. In: Katan, J.; DeVay, J.E. Soil solarization. Boca Raton: CRC, 1991. cap.3, p.39-50.

5. Flechter J.T. Diseases of greenhouse plants. Essex:Longman, 1984. $335 \mathrm{p}$

6. Garibaldi, A.; Tamietti, G. Solar heating: recent results obtained in northern Italy. Acta Horticulturae, Leuven, v. 255, p.125-129, 1989.

7. Griffin, G.J.; Baker, R. Population dinamics of plant pathogens and associated organisms in soil in relation to infectious inoculum. In: Katan, J.; DeVay, J.E. Soil solarization. Boca Raton: CRC, 1991. cap.1, p.4-21, 1991.

8. Gulino, M.L.; Camponogara, A.; Gasparrini, G.; Clini, C.; Garibaldi, A. Replacing methyl bromide for soil disinfestation. The Italian experience and implications for other countries. Plant Disease, St. Paul, v. 87, n.9, p.1012-1020, 2003.

9. Gulino, M.L.; Minuto, A.; Garibaldi, A. Improved method of bench solarization for the control of soilborne diseases in basil. Crop Protection, London, v.17, n.6, p.497-501, 1998

10. Kaewruang, W.; Sivasithamparm K.; Hardy, G.E. Effect of solarization of soil within plastic bags on root rot of gerbera (Gerbera jamesonii L.). Plant and Soil, The Hage, v.120, p.303-306, 1989.

11. Katan, J. Methyl bromide: problems and solutions. Journal of Plant Pathology, v.81, p.153-159, 1999.

12. Katan, J. Soil solarization: integrated control aspects. In: Hall, R. (Ed.). Principles and practices of managing soilborne plant pathogens, St. Paul: APS, 1996. cap.12, p. 213-236.

13. Katan, J.; DeVay, J.E. Soil solarization; historical perspectives, principles and uses. In: Katan, J.; DeVay, J.E. Soil solarization. Boca Raton: CRC, 1991. cap.2, p.24-37.

14. Koch, E. Evaluation of commercial products for microbial control of soil-borne plant diseases. Crop Protection, London, v.18, p.119$125,1999$.

15. Latorre, B.A. Cucurbitaceae, enfermedades. In: Latorre, B; Vaughan, M.A. \& Aguilar, P.G. Plagas de las hortalizas: manual de manejo integrado. Santiago: FAO, 1990. cap.4, p.155-180.

16. Lefèvre, A.F.V.; Souza, N.L. Determinação da temperatura letal para Rhizoctonia solani e Sclerotium rolfsii e efeito da solarização sobre a temperatura do solo. Summa Phytopathologica, Jaboticabal, v.19, n.2, p.107-112, 1993.

17. Lopes, M.E.B.M.; Ghini, R.; Tessariolli, J.; Patrício, F.R.A. Solarização do solo para o controle de Pythium spp. na cultura do pepino em cultivo protegido. Summa Phytopathologica, Botucatu, v.26, p.224-227, 2000.

18. Lourd, M.; Alves, M.L.B; Bouhot, D. Análise qualitativa e quantitativa de espécies de Pythium patogênicas dos solos no município de Manaus. I. Solos de terra firme. Fitopatologia Brasileira, Brasília, v.11, n.9, p.479-485, 1986.

19. Mahrer, Y. Physical principles of solar heating of soils by plastic mulching in the field and in glasshouses and simulation models. In: Katan, J.; DeVay, J.E. Soil solarization. Boca Raton: CRC, 1991. cap.6, p.76-86.

20. Minuto, A.; Migheli, Q.; Garibaldi, A. Integrated control of soilborne plant pathogens by solar heating and antagonistic microrganisms. Acta Horticulturae, Leuven, v.382, p.139-143, 1995.

21. Ousley, M.A., Lynch, J.M., Whipps, J.M. Potential of Trichoderma spp. as consistent plant growth stimulators. Biology and Fertility of Soils, Oxford, v. 17, n.2, p.85-90, 1994.

22. Patrício, F.R.A.; Kimati, H.; Barros, B.C. Seleção de isolados de Trichoderma spp. antagônicos a Pythium aphanidermatum e Rhizoctonia solani. Summa Phytopathologica, Jaboticabal, v. 27, p. 223-229, 2001.

23. Patrício, F.R.A.; Lopes, M.E.B.M.; Malavolta, V.M.A.; Sinigaglia, C.; Peterossi Jr., N. Controle químico do tombamento causado por Pythium aphanidermatum em plântulas de melão, pepino, repolho e tomate. Revista de Agricultura, Piracicaba, v. 77, n.1, p.139$150,2002$.

24. Pereira, J.C.R.; Chaves, G.M.; Zambolim, L.; Matsuoka, K.; Acuña, R.S.; Vale, F.X.R. do. Controle de Sclerotium cepivorum Berk. pelo uso combinado de vermicomposto, solarização, Trichoderma harzianum e Bacillus subtilis. Summa Phytopathologica, Jaboticabal, v.22, p. 228-234, 1996.

25. Pullmann, G.S.; DeVay, J.E.; Garber, R.H.; Weinhold, A.R. Soil solarization: effects on verticillium wilt of cotton and soilborne populations of Verticillium dahliae, Pythium spp., Rhizoctonia solani and Thielaviopsis basicola. Phytopathology, St. Paul, v.71, n.9, p.954959, 1981.

26. Raftoyannis, Y., Dick, M.W. Effects of inoculum density, plant age and temperature on disease severity caused by pythiaceous fungi on several plants. Phytoparasitica, Tel Aviv, v. 30 , n.1, p. 67-76, 2002 .

27. Ristaino, J.B.; Thomas, W. Agriculture, methyl bromide, and the ozone hole. Can we fill the gaps? Plant Disease, St. Paul, v.81, n.9, p. 964-977, 1997.

28. Sinigaglia, C.; Patrício, F.R.A.; Ghini, R., Malavolta, V.M.A.; Tessarioli, J.; Freitas, S.S. Controle de Sclerotinia minor, Rhizoctonia solani e plantas daninhas pela solarização do solo e sua integração com controle químico. Summa Phytopathologica, Jaboticabal, v. 27, p.229-235, 2001

29. Stapleton, J.J.; DeVay, J.E. Soil solarization: a natural mechanism of integrated pest management. In: Reuveni, R. (Ed.). Novel aproaches to integrated pest management. Boca Raton:CRC, 1995. cap.15, p.309-350.

30. Tjamos, E.C.; Karapapa, V.; Bardas, D. Low cost application of soil solarization in covered plastic houses for the control of Verticillium wilt in tomatoes in Greece. Acta Horticulturae, Leuven, v. 255, p.139-149, 1989 